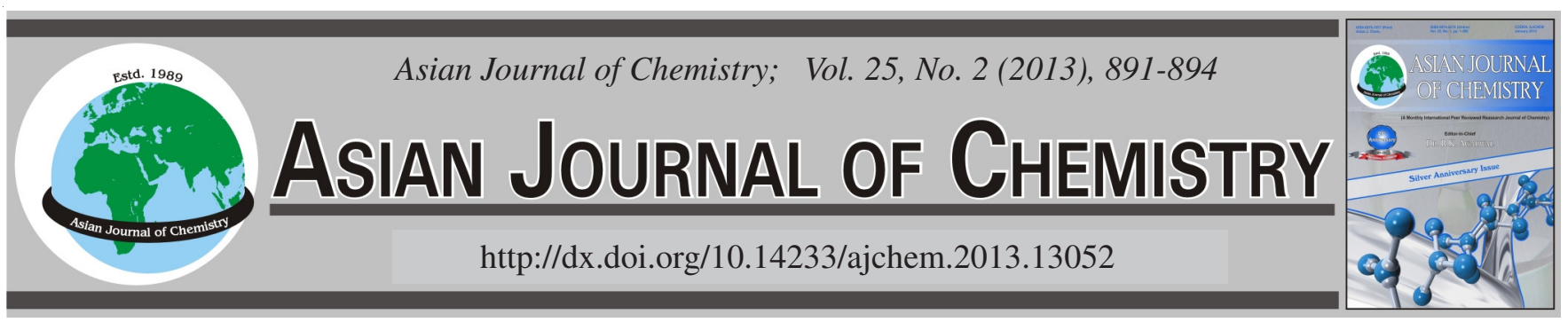

\title{
Differential Effect of Metal Ions on Antibacterial Activity of Chitosan Against Burkholderia cenocepacia
}

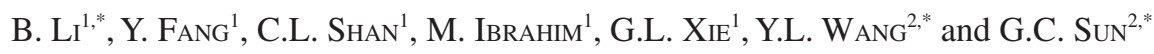

${ }^{1}$ State Key Laboratory of Rice Biology, Key Laboratory of Molecular Biology of Crop Pathogens and Insects, Ministry of Agriculture, Institute of Biotechnology, Zhejiang University, Hangzhou 310029, P.R. China

${ }^{2}$ State Key Laboratory Breeding Base for Zhejiang Sustainable Pest and Disease Control, Institute of Plant Protection and Microbiology, Zhejiang Academy of Agricultural Sciences, Hangzhou 310021, P.R. China

*Corresponding authors: Fax: +86 571 86404225; Tel: +86 571 86404073; E-mail: libin0571@zju.edu.cn; wangylaa@yahoo.com.cn; sungc@zaas.org

\begin{abstract}
In this study, the antibacterial activity of chitosan and chitosan metal salts against Burkholderia cenocepacia isolated from cystic fibrosis patients was investigated. Results showed that chitosan solution at $0.01,0.05$ and $0.10 \mathrm{mg} / \mathrm{mL}$ markedly inhibited the growth of $B$. cenocepacia Y10 although the antibacterial activity decreased with the increase of chitosan concentration. However, the antibacterial activity of chitosan solution against $B$. cenocepacia Y20 increased with the increase of chitosan concentration up to $0.05 \mathrm{mg} / \mathrm{mL}$. In addition, the antibacterial activity of chitosan solution against $B$. cenocepacia strains was decreased by $\mathrm{NaCl}, \mathrm{CaCl}_{2}$ and $\mathrm{MgCl}_{2}$. $\mathrm{However}$, both $\mathrm{ZnCl}_{2}$ and $\mathrm{FeCl}_{3}$ significantly enhanced the antibacterial activity of chitosan solution regardless of the tested bacterial strains. Overall, the results indicated that chitosan-Zn or chitosan-Fe complex may be a promising candidate for novel antimicrobial agents in pharmaceutical industry.
\end{abstract}

Key Words: Antibacterial activity, Burkholderia cenocepacia, Chitosan, Concentration, Metal ions.

(1)

\section{INTRODUCTION}

Cystic fibrosis (CF) is the most common life-threatening autosomal recessive disease, affecting more than 50,000 individuals worldwide with an incidence of 1 in 3200 live births ${ }^{1,2}$. Most of the infections in cystic fibrosis patients occur with Burkholderia cenocepacia strains, which can be transmitted from patient to patient and the infection often results in rapid deterioration of the lung and a life-threatening pneumonia termed "cepacia syndrome"1. Treatment of these infections is very difficult because of the intrinsic resistance of $B$. cenocepacia to most clinically useful antibiotics and it even can actually utilize penicillin $\mathrm{G}$ as a sole carbon source for growth ${ }^{3}$. Thus, it becomes important to identify newer and improved antibacterial drugs for patients with cystic fibrosis.

Chitosan is a natural non-toxic biopolymer derived by deacetylation of chitin [poly- $\beta$ - $(1 \rightarrow 4)-\mathrm{N}$-acetyl-D-glucosamine], a major component of the shells of crustacea such as crab, shrimp and crawfish ${ }^{4}$. In recent years, applications of chitosan to the fields of medicine, food, chemical engineering, pharmaceuticals, nutrition, environmental protection and agriculture have received considerable attention ${ }^{4}$. In addition, chitosan has several advantages over other type of bactericide because it possesses a higher antibacterial activity, a broader spectrum of activity, a higher killing rate and a lower toxicity toward mammalian cells ${ }^{4}$. Several studies have demonstrated that chitosan had strong antibacterial activity against humanassociated bacteria ${ }^{5,6}$. However, the antimicrobial activity of chitosan against $B$. cenocepacia was not clear.

Many attempts have also been taken up to improve the antimicrobial activity of chitosan, such as structural modification, adjustment of molecular factors and forming complexes with other antimicrobial materials ${ }^{7,8}$. It has been well documented that chitosan is a powerful chelating agent, which is easy to form complexes with transition metals and heavy metals ${ }^{9}$. Most researches of chitosan-metal complexes focused on their applications in the sequestration or removal of metal ions, dyeing, catalysis, water treatment and many other industrial processes ${ }^{8}$. Recently, few researches pay attention to their biological activities and found that the complexes showed wide spectra antimicrobial activities, which were much higher than free chitosan and metal salts?

The objective of this research was to evaluate the antibacterial activity of chitosan treated with different metal salts 
solution against $B$. cenocepacia isolated from cystic fibrosis patients.

\section{EXPERIMENTAL}

Chitosan (degree of N-deacetylation no less than $85 \%$, practical grade, from crab shells) was obtained from SigmaAldrich (St. Louis, MO, USA). Sodium hydroxide, sodium chloride, calcium chloride, magnesium chloride, zinc chloride, ferric chloride and acetic acid were of analytical grade and supplied by Shanghai Sangon Biological Engineering Technology and Services Co., Ltd. (Shanghai, China). Stock solution of chitosan $(5 \mathrm{mg} / \mathrm{mL})$ was prepared in $1 \%$ acetic acid with pH being adjusted ${ }^{4}$ to 6.0 with $\mathrm{NaOH}$. After stirring ( $160 \mathrm{rpm}$ ) for $24 \mathrm{~h}$ at room temperature, the stock solution was autoclaved at $121{ }^{\circ} \mathrm{C}$ for $20 \mathrm{~min}$. Sterile deionized water of $\mathrm{pH} 6$ was used as a control.

Cultivation of the microorganism: Two strains of $B$. cenocepacia (Y10 and Y20) were kindly provided by First Affiliated Hospital of China Medical University, which were isolated from the sputum of cystic fibrosis patients. All bacterial strains involved in this study were deposited in the culture collection of the Institute of Biotechnology, Zhejiang University, China. The bacterial strains were cultured for $48 \mathrm{~h}$ on nutrient agar medium ${ }^{4}$ at $28^{\circ} \mathrm{C}$. After incubation, each bacterial suspension was prepared in sterilized water and the initial concentration of bacteria was adjusted to $c a .10^{9}$ colony forming units $(\mathrm{cfu}) / \mathrm{mL}$.

Counting surviving cells: Bacterial suspensions were ten-fold serially diluted and $10 \mu \mathrm{L}$ samples were inoculated on nutrient agar medium in hexaplicate for each dilution and were incubated for $48 \mathrm{~h}$ at $28^{\circ} \mathrm{C}$. After incubation, the surviving cells on the agar were counted based on the colony forming units and then the mean value of the cells at the lowest dilution was calculated. Each experiment was carried out in duplicate and was replicated twice.

Effect of chitosan concentration on the antibacterial activity: Chitosan solutions of $5 \mathrm{~mL}$ in volume were prepared by adding chitosan stock to deionized water to give a final chitosan concentration of $0.01,0.05$ and $0.10 \mathrm{mg} / \mathrm{mL}$. Bacterial solution was added to $5 \mathrm{~mL}$ of chitosan solution to give a final bacterial concentration of $10^{8} \mathrm{cfu} / \mathrm{mL}$ and then the mixture was incubated at $28^{\circ} \mathrm{C}$ on a rotary shaker (Hualida Company, Taicang, China) at $160 \mathrm{rpm}$. In the control treatment chitosan stock was replaced with sterile deionized water of $\mathrm{pH} 6$ in order to obtain the same $\mathrm{pH}$. After $6 \mathrm{~h}$, samples were collected from each cell suspension and bacterial counting was followed as indicated above.

Effect of metal ions on the antibacterial activity of chitosan: Chitosan solutions of $5 \mathrm{~mL}$ in volume were prepared by adding $100 \mu \mathrm{L}$ chitosan stock to $4.90 \mathrm{~mL}$ deionized water with different metal ions to give a final chitosan concentration of $0.10 \mathrm{mg} / \mathrm{mL}$. The final concentration of the metal ions was adjusted to 15 and $30 \mathrm{mM}$, respectively, by adding a metal aqueous solution of $\mathrm{NaCl}, \mathrm{MgCl}_{2} \cdot 6 \mathrm{H}_{2} \mathrm{O}, \mathrm{CaCl}_{2} \cdot 2 \mathrm{H}_{2} \mathrm{O}, \mathrm{ZnCl}_{2}$ or $\mathrm{FeCl}_{3} \cdot 6 \mathrm{H}_{2} \mathrm{O}$ to the chitosan solution. B. cenocepacia $\mathrm{Y} 10$ and Y20 were separately inoculated into chitosan solution to give a final bacterial concentration of $10^{8} \mathrm{cfu} / \mathrm{mL}$ and then the mixture was incubated at $28{ }^{\circ} \mathrm{C}$ on a rotary shaker at $160 \mathrm{rpm}$.
In the control treatment chitosan stock was replaced with sterile deionized water of $\mathrm{pH} 6$ in order to obtain the same $\mathrm{pH}$. After $6 \mathrm{~h}$, samples were collected from each cell suspension and bacterial counting was followed as indicated above.

Statistical analysis: The software STATGRAPHICS Plus, version 4.0 (Copyright Manugistics Inc., Rockville, Md., USA) was used to perform the statistical analysis. Levels of significance $(p<0.05)$ of main treatments and their interactions were calculated by analysis of variance after testing for normality and variance homogeneity.

\section{RESULTS AND DISCUSSION}

Chitosan solution at three different concentrations showed effective antibacterial activity against the strain Y10 of $B$. cenocepacia compared to the control after $6 \mathrm{~h}$ of incubation (Fig. 1). At the concentration of $0.01 \mathrm{mg} / \mathrm{mL}$, chitosan exhibited the maximum antibacterial activity. The surviving cell numbers in chitosan solution of $0.01 \mathrm{mg} / \mathrm{mL}$ decreased $2.17 \log _{10} \mathrm{cfu} / \mathrm{mL}$, while the surviving cell numbers in chitosan solution of $0.05 \mathrm{mg} / \mathrm{mL}$ decreased $1.41 \log _{10} \mathrm{cfu} / \mathrm{mL}$ compared to the control. As shown in Fig. 2, chitosan solutions up to $0.05 \mathrm{mg} / \mathrm{mL}$ showed stronger antibacterial activity against the strain Y20 of B. cenocepacia compared with the remainder treatment, which is consistent with the result of Liu et al. ${ }^{10}$, who found that the antibacterial activity of chitosan was influenced by its concentration in the solution. The surviving cell numbers in chitosan solution of $0.05 \mathrm{mg} / \mathrm{mL}$ decreased $1.40 \log _{10} \mathrm{cfu} / \mathrm{mL}$, while the surviving cell numbers in chitosan

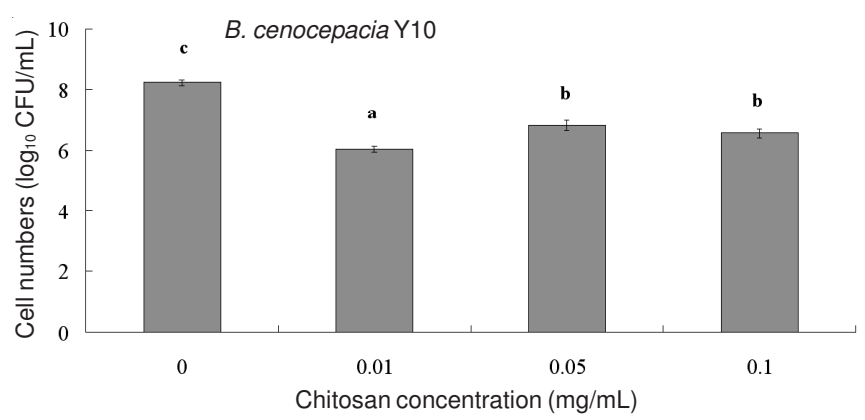

Fig. 1. Effect of chitosan concentration on the antibacterial activity of strain Y10 of B. cenocepacia isolated from cystic fibrosis patients. Columns with the same letters are not significantly different $(p<$ 0.05 ). Error bars represent the standard error of the mean. Data are from a representative experiment repeated twice with similar results

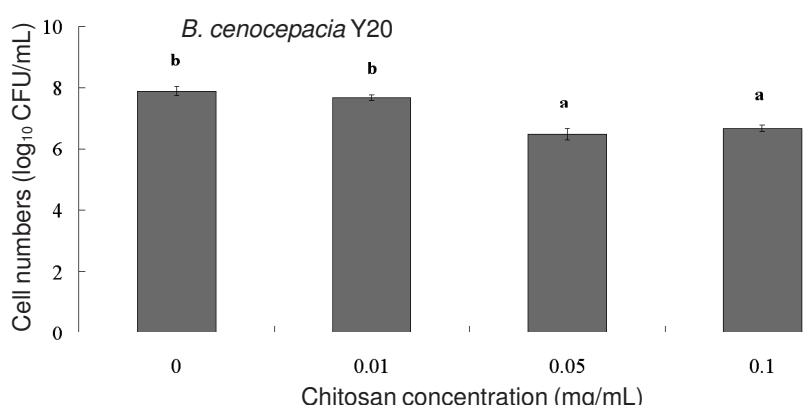

Fig. 2. Effect of chitosan concentration on the antibacterial activity of strain Y20 of B. cenocepacia isolated from cystic fibrosis patients. Columns with the same letters are not significantly different $(p<$ 0.05). Error bars represent the standard error of the mean. Data are from a representative experiment repeated twice with similar results 
solution of $0.01 \mathrm{mg} / \mathrm{mL}$ decreased only $0.21 \log _{10} \mathrm{cfu} / \mathrm{mL}$ compared to the control. Concentrations higher than $0.05 \mathrm{mg} /$ $\mathrm{mL}$ were not significantly different, which is a little different from the antibacterial activity of chitosan against the strain Y10 of B. cenocepacia.

The antibacterial activity of chitosan decreased with the increase in concentration of chitosan may be attributed to the increase in the ionic strength of the solution for $\mathrm{NaOH}$ was added to adjust the $\mathrm{pH}$ of the chitosan stock, which is consistent with the result of Devlieghere et al. ${ }^{11}$, who found that $\mathrm{NaCl}$ had a negative effect on the antimicrobial activity of chitosan. However, this is inconsistent with the study of Chung et al. ${ }^{12}$, who found that a higher ionic strength may enhance the solubility of chitosan and thus increases its antibacterial activity. The difference may be due to a number of factors, such as characteristics of the chitosan, the tested microorganism and $\mathrm{NaCl}$ concentration used in these studies.

Metal ions of many kinds are ubiquitous in the human body and exist in abundance in the natural environment. It is also well known that metal ions form an important group of antimicrobial agents, which have different active target from most bacteriostatic polymers. Wang et al. ${ }^{13}$ found that the chitosan-metal complexes showed wide spectra antimicrobial activities, which were much higher than free chitosan and metal salts. However, metal ions were also found to reduce the antibacterial activity of chitosan derivative. Yang et al. ${ }^{14}$ found that the addition of metal salts reduced the antibacterial activity of chitosan derivative against Escherichia coli. Furthermore, Bassi et al..$^{15}$ demonstrated that the decrease of the antibacterial activity was due to chelation of chitosan with the metal ions.

The effect of different metal ions on antibacterial activity of chitosan against $B$. cenocepacia is shown in Table-1, which showed that different metal ions had differential effect on antibacterial activity of chitosan. The addition of $\mathrm{NaCl}$ at the final concentrations of 15 and $30 \mathrm{mM}$ dramatically decreased the antibacterial activity of chitosan solution, which is consistent with the result of Devlieghere et al. ${ }^{11}$, who found that $\mathrm{NaCl}$ had a negative effect on the antimicrobial activity of chitosan. Similarly, the antibacterial activity of chitosan solution at $0.10 \mathrm{mg} / \mathrm{mL}$ against $B$. cenocepacia $\mathrm{Y} 10$ and $\mathrm{Y} 20$ was decreased by $\mathrm{MgCl}_{2}$ or $\mathrm{CaCl}_{2}$, which is consistent with the result of Chung et al. ${ }^{12}$, who found that the addition of $\mathrm{CaCl}_{2}$ or $\mathrm{MgCl}_{2}$ at a final concentration of $25 \mathrm{mM}$ clearly interfered with the antibacterial activity of chitosan. Interestingly, the results of the present study indicate that the growth of B. cenocepacia Y10 and Y20 were completely inhibited by chitosan amended with $\mathrm{ZnCl}_{2}$ or $\mathrm{FeCl}_{3}$ at the final concentrations of 15 and $30 \mathrm{mM}$, which is different with the result of Chung et al. ${ }^{12}$, who found that the existence of $\mathrm{ZnCl}_{2}$ at a final concentration of $25 \mathrm{mM}$ clearly interfered with the antibacterial activity of chitosan.

In recent years, chitosan-metal complex attracted great interests for its potential use as medicament or nutriment ${ }^{16}$. It is well known that both chitosan and some metal salts have the properties of disinfection and bactericide ${ }^{17}$. After chitosan binds to some metal ions through nitrogen, oxygen or a combination of them, the bindings are likely to leave some potential donor atoms free and these free donor atoms enhance the

\section{TABLE-1}

EFFECT OF METAL IONS ON THE ANTIBACTERIAL ACTIVITY OF CHITOSAN SOLUTION AT $0.10 \mathrm{mg} / \mathrm{mL}$ AGAINST B. cenocepacia Y10 AND Y20

\begin{tabular}{ccc}
\hline \multirow{2}{*}{$\begin{array}{c}\text { Chitosan solution } \\
\text { amended with }\end{array}$} & \multicolumn{2}{c}{$\begin{array}{c}\text { Reduction in surviving cell } \\
\text { numbers }\left(\log _{10} \text { cfu/mL }\right)\end{array}$} \\
\cline { 2 - 3 } & B. cenocepacia Y10 & B. cenocepacia Y20 \\
\hline None & $1.36 \pm 0.07$ & $1.17 \pm 0.05$ \\
$\mathrm{NaCl}$ at $15 \mathrm{mM}$ & $0.28 \pm 0.03$ & $0.57 \pm 0.04$ \\
$\mathrm{NaCl}$ at $30 \mathrm{mM}$ & $0.39 \pm 0.04$ & $0.38 \pm 0.06$ \\
$\mathrm{CaCl}_{2}$ at $15 \mathrm{mM}$ & $0.43 \pm 0.04$ & $0.35 \pm 0.05$ \\
$\mathrm{CaCl}_{2}$ at $30 \mathrm{mM}$ & $0.39 \pm 0.05$ & $0.41 \pm 0.04$ \\
$\mathrm{MgCl}_{2}$ at $15 \mathrm{mM}$ & $0.64 \pm 0.03$ & $0.23 \pm 0.05$ \\
$\mathrm{MgCl}_{2}$ at $30 \mathrm{mM}$ & $0.76 \pm 0.05$ & $0.11 \pm 0.05$ \\
$\mathrm{ZnCl}_{2}$ at $15 \mathrm{mM}$ & $8.11 \pm 0.06$ & $8.03 \pm 0.06$ \\
$\mathrm{ZnCl}_{2}$ at $30 \mathrm{mM}$ & $8.11 \pm 0.06$ & $8.03 \pm 0.06$ \\
$\mathrm{FeCl}_{3}$ at $15 \mathrm{mM}$ & $8.11 \pm 0.06$ & $8.03 \pm 0.06$ \\
$\mathrm{FeCl}_{3}$ at $30 \mathrm{mM}$ & $8.11 \pm 0.06$ & $8.03 \pm 0.06$ \\
\hline $\mathrm{The}^{2}$
\end{tabular}

The data were shown as means \pm standard error from a representative experiment repeated twice with similar results. Initial concentration of B. cenocepacia $\mathrm{Y} 10$ and $\mathrm{Y} 20$ is approximately $10^{8} \mathrm{cfu} / \mathrm{mL}$. The surviving cells in chitosan solution were counted after $6 \mathrm{~h}$ of inocubation. Each value represents the average of six replicates.

biological activity ${ }^{13}$. So it stands a good chance that chitosanmetal complex exhibit enhanced ability of antimicrobial, which will be very favourable to chitosan-metal complex' applications in medical industry and food industry ${ }^{13}$.

\section{Conclusion}

Present data demonstrated that the chitosan could inhibit the growth of B. cenocepacia isolated from the sputum of cystic fibrosis patients. To the best of our knowledge, this is the first report about antibacterial activities of chitosan on B. cenocepacia, which showed chitosan has potential as a therapeutic strategy against bacterial infections in cystic fibrosis. Results in this study further indicated that the inhibitory effects of chitosanmetal complexes were dependent on the property of metal ions. Both $\mathrm{ZnCl}_{2}$ and $\mathrm{FeCl}_{3}$ significantly enhanced the antibacterial activity of chitosan solution while the antibacterial activities of chitosan solution were reduced by $\mathrm{NaCl}, \mathrm{CaCl}_{2}$ and $\mathrm{MgCl}_{2}$. In addition, chitosan-metal complexes are obviously safer for human health and the environment than free metal ions, which showed that chitosan-Zn or chitosan-Fe complex may be a good candidate for novel antimicrobial agents in pharmaceutical industry.

\section{ACKNOWLEDGEMENTS}

This project was supported by Zhejiang Provincial Natural Science Foundation of China (Y3090150), Zhejiang Provincial Project (2010R10091), the Fundamental Research Funds for the Central Universities, the Agricultural Ministry of China (nyhyzx 201003029; 201003066), State Education Ministry and Key Subject Construction Program of Zhejiang for Modern Agricultural Biotechnology and Crop Disease Control.

\section{REFERENCES}

1. S.P. Bernier and P.A. Sokol, J. Bacteriol., 187, 5278 (2005).

2. L.X. Zhang and G.L. Xie, FEMS Microbiol. Lett., 266, 231 (2007).

3. S.T. Cardona, C.L. Mueller and M.A. Valvano, Appl. Environ. Microbiol., 72, 2547 (2006). 
4. B. Li, X. Wang, R.X. Chen, W.G. Huangfu and G.L. Xie, Carbohydr. Polym., 72, 287 (2008).

5. T. Fujimoto, Y. Tsuchiya, M. Terao, N. Nakamura and M. Yamamoto, Int. J. Food Microbiol., 112, 96 (2006).

6. J. Šimunek, G. Tishchenko, B. Hodrova and H. Baptonová, Folia Microbiol., 51, 306 (2006).

7. C.P. Dhanalakshmi, L. Vijayalakshmi and V. Narayanan, Asian J. Chem., 24, 5264 (2012).

8. X.Y. Wang, Y.M. Du, J.H. Yang, X.H. Wang, X.W. Shi and Y. Hu, Polymer, 47, 6738 (2006)

9. A. Webster, M.D. Halling and D.M. Grant, Carbohydr. Res., 342, 1189 (2007).

10. N. Liu, X.G. Chen, H.J. Park, C.G. Liu, C.S. Liu, X.H. Meng and L.J. Yu, Carbohydr. Polym., 64, 60 (2006).
11. F. Devlieghere, A.Vermeulen and J. Debevere, Food Microbiol., 21, 703 (2004).

12. Y.C. Chung, H.L. Wang, Y.M. Chen and S.L. Li, Bioresour. Technol., 88, 179 (2003).

13. X.H. Wang, Y.M. Du and H. Liu, Carbohydr. Polym., 56, 21 (2004).

14. T.C. Yang, C.F. Li and C.C. Chou, Int. J. Food Microbiol., 113, 258 (2007).

15. R. Bassi, S.O. Prasher and B.K. Simpson, J. Environ. Sci. Health, Part A: Toxic/Hazard Subst. Environ. Eng., 34, 289 (1999).

16. J.L. Roerig, J.E. Mitchell, M. de Zwaan, S.A. Wonderlich, S. Kamran, S. Engbloom, M. Burgard and K. Lancaster, Int. J. Eat. Disorder, 33, 443 (2003).

17. Y. J. Jeon and S. K. Kim, Carbohydr. Polym., 41, 133 (2000). 